\title{
Diet composition and body size in insect herbivores: Why do small species prefer young leaves?
}

\author{
LUKÁš ČÍŽEK \\ Institute of Entomology, Czech Academy of Sciences, Branišovská 31, 37005 České Budějovice, Czech Republic; \\ e-mail: cizek@entu.cas.cz
}

Key words. Body size, constraint, diet composition, herbivory, insect, leaf toughness, Papua New Guinea, phenology, specificity, plant defence, young leaves

\begin{abstract}
The hypothesis that small body size is correlated with preference for young leaves was tested in a community of leafchewing insect herbivores feeding on Ficus wassa in a humid tropical forest in Papua New Guinea. Feeding experiments on 48 species of herbivorous insects revealed a negative correlation between body size and a preference for feeding on young leaves. While small species preferred young leaves, large species showed no preferences, or preferred young leaves only slightly. This relationship was found for the entire leaf-chewing community, as well as for many of the constituent taxa on several taxonomic levels, from orders to genera. Taxonomic position of a species played little role in determining its preferences. It is proposed that higher toughness and lower nutrient content may act as complementary defences, which prevent small insects from feeding on mature foliage. While the low nutrient content of mature leaves may affect smaller herbivores due to their relatively higher metabolic rate and lower digestion efficiency, their toughness complicates feeding mechanically and may prevent the compensatory feeding necessary to offset the low nutritive value of mature leaves.
\end{abstract}

\section{INTRODUCTION}

Young leaves are a key resource for insect as well as vertebrate herbivores (Feeny, 1970; Coley, 1983; Yela \& Herrera, 1993; Usongo \& Amubode, 2001). In comparison with mature leaves, they contain more water and organic nitrogen, which is a limiting nutrient for many insect herbivores. Furthermore, young leaves are not as tough as mature leaves (Scriber \& Slansky, 1981; Choong, 1996; Coley \& Barone, 1996). The spatial and temporal distribution of many herbivorous insects coincides with the distribution of young foliage (Aide, 1988; Basset, 1991a, b; Van Dongen et al., 1997; Barone, 2000), which provides indirect evidence of their preference or dependence on young leaves. Data on the relative preference of insect herbivores for young and mature foliage, however, are not available at the community level. It is, therefore, unclear which life history traits, if any, are correlated with preference for young or mature leaves. The present study measures the preference for young relative to mature leaves in a community of externally leafchewing insects in a humid lowland forest in Papua New Guinea, with particular reference to body size as a possible determinant.

Body size is an important determinant of animal diet. In particular, small species of vertebrate herbivores tend to feed on diets richer in nutrients than large species (Fleming, 1991; Hume et al., 1993; Hirakawa, 1997). Analogous trends are also found for conspecific individuals of different body size (Benavidess et al., 1994; Conradt et al., 1999; Agetsuma, 2001). This has been attributed to allometric decrease in digestive efficiency and increase in specific metabolic rate with decreasing body size (Kleiber, 1975; Demment \& Van Soest, 1985).
Invertebrates are subject to similar allometric constraints as vertebrates, although specific mechanisms increasing digestion efficiency in small species (Yang \& Joern, 1994a; Woods, 1999; Ahrens et al., 2001) may ameliorate the negative consequences of body size on digestive efficiency. It is hypothesized that small invertebrates require richer diets than their larger relatives. No community-wide analysis of the relationship between body size and diet quality is available for invertebrates, with the exception of termites (Eggleton et al., 1998). There is anecdotal information indirectly supporting the negative body size - diet quality relationship, but it is limited to one or a few species, rather than addressing community patterns (Yang \& Joern, 1994a; Woods, 1999; but see Novotný \& Wilson, 1997). The hypothesis on the negative relationship between body size and food quality, measured as the preference for young leaves, is tested in the present study, using data on a community of leaf chewing insects.

\section{MATERIAL AND METHODS}

\section{Insect sampling and feeding tests}

The study was carried out in Madang Province (Papua New Guinea) in primary and secondary lowland forests near Baitabag, Ohu, and Mis Villages $\left(145^{\circ} 41-8^{\prime} \mathrm{E}, 5^{\circ} 08-14^{\prime} \mathrm{S}\right.$, ca. 0-200 m a.s.1.). For details on climate see McAlpine et al. (1983). All externally feeding, leaf-chewing insects (Coleoptera: Chrysomelidae and Curculionidae, Lepidoptera and orthopteroids, i.e. Orthoptera and Phasmatodea), including leaf rollers, were collected by hand from the foliage of Ficus wassa Roxburgh (Moraceae). At three study sites (one near each village), numerous $(>100)$ individual trees were sampled in an approximately $5 \mathrm{~km}^{2}$ of primary and secondary forest. Insects were collected in parallel at the three sites one day a week from May 1999 to August 2000, i.e. on approximately 190 collecting days. 
Ficus wassa is one of the locally most common fig species. It is distributed in both secondary and primary forest (Lepš et al., 2001). This small tree has one of the most species-rich communities of leaf-chewing herbivores among the 59 tree species studied by Basset \& Novotný (1999) and Novotný et al. (2002). Leaf expansion of $F$. wassa takes about 25 days (Basset \& Novotný, 1999). Leaf flush is synchronized within, but not among, trees, thus creating a continuously available supply of young leaves. F. wassa, as many New Guinea Ficus species, but unlike many other trees, exhibits a clear difference between young and mature leaves. Young, expanding leaves are light green and tender, while fully expanded mature leaves become darker and tough within a short period of time (pers. observ.). Leaves were collected from many individual trees. The young and mature leaves offered to an insect originated from the same tree.

Each insect was placed individually in a plastic container and offered a choice between equally-sized pieces of young and mature leaves of $F$. wassa. The containers were spacious enough to allow free movement of even large insects and kept in a shady room, where light and temperature reflected the outside conditions. The experiments were performed ex situ, on freshly cut leaves. Leaves were replaced with fresh ones after $24 \mathrm{~h}$. Every insect was tested only once and was kept in the container until it fed, died, or, in the case of caterpillars, pupated. Insects that did not feed were discarded. The caterpillars were reared to the adult stage when possible. Feeding was scored after 12 hours, and recorded as follows: (i) exclusively fed on a young leaf, (ii) fed on both leaves with a clear preference for young leaf (the damage to young leaf was at least twice that to mature leaf), (iii) fed approximately equally on both leaves, (iv) fed on both leaves with a clear preference for mature leaf (the damage to mature leaf was at least twice that to young leaf), or (v) exclusively fed on mature leaf. Only leaf damage that was larger in area than the pronotum of the tested specimen was counted.

Feeding experiments on ex situ leaves can give different results from those performed on live plants, particularly for latex-producing species (Dussourd \& Denno, 1991; Farrel et al., 1991). The interruption of latex flow in excised leaves is, however, unlikely to bias the results. A series of feeding experiments on in situ and ex situ leaves of 15 Ficus species, including $F$. wassa, gave similar results (Basset \& Novotný, 1999). In addition, leaves of $F$. wassa contain little latex (Basset \& Novotný, 1999) and there is no difference in the latex content of young and mature leaves (pers. observ.).

All insects were assigned to morphospecies, which were subsequently verified by taxonomists and identified as far as possible. Voucher specimens are deposited in the National Insect Collection of the National Agriculture Research Institute, Port
Moresby; Bishop Museum, Honolulu; and National Museum of Natural History, Smithsonian Institution, Washington D.C.

\section{Data analysis}

Only species for which there were more than 5 test results were analysed. This minimum sample size was set arbitrarily. It was a compromise between the need to maximize the number of species analyzed and the necessity to obtain reliable estimates of feeding preference. The preference of each species was quantified by the preference for young leaves index,

$$
Y_{i}=\left(A i+0.75 B_{i}+0.5 C_{i}+0.25 D_{i}\right) / N_{i}
$$

where $A, B, C$ and $D$ are numbers of tests, when specimens of species $i$ fed on: young leaves exclusively $(A)$; both types of leaves, but preferred young ones $(B)$; both types without preference $(C)$; both types, but preferred mature ones $(D)$ respectively. $N_{i}$ is the total number of tests performed on species $i$. The index reflects the relative amount of young leaves consumed, and ranges from 0 (mature leaf specialists) through 0.5 (indiscriminate feeding on both young and mature leaves) to 1 (young leaf specialists).

Body size was quantified by the index, $B=L^{*} T^{2}$ (in $\mathrm{mm}^{3}$ ), where $L$ is the body length (excluding extremities such as antennae, horns and spines) and $T$ the thorax width. Five individuals per species were measured and the mean values of $L$ and $T$ were than used to calculate $B$. Due to differences in insect body shape, $B$ is an approximation of the insect's volume. The largest leaf-chewing stage was measured for each species (i.e. adults in Coleoptera, Orthoptera and Phasmatodea, and the final caterpillar instar in Lepidoptera). The great majority of individuals tested were in these stages.

Multiple regression was used to determine the effect of body size and taxonomic position (insect order) on feeding preferences. The preference index, $Y$, was regressed against insect order (categorical predictor), body size index, $B$, (continual predictor) and their interaction, using generalized linear modeling (S-plus 2000, 1999). Preference index, $Y$, and body size, $B$, were normalized by arcsine and logarithmic transformation, respectively. A normal distribution of the transformed response variable was assumed (link function identity). Following single-term regressions and construction of the model with interaction, the most parsimonious combination of predictors was selected comparing individual models according to values of Akaike information criteria (AIC).

For higher taxa for which at least 5 species were tested, the relationship between the preference index, $Y$, and the body size index, $B$, was also tested, using a linear regression $Y=a+b$ $\ln B$. The selection includes orders, families and a genus (listed in Table 2).

TABLE 1. Regression of the preference for young leaves $(Y)$ on the body size and taxonomic position (insect order) of herbivorous species feeding on Ficus wassa (generalized linear models with assumed gaussian distribution). Note that the table does not summarize a hierarchical analyses, and that $\mathrm{P}$ and $\mathrm{F}$ values refer to comparison of fitted models with a null model $Y \sim+1$.

\begin{tabular}{lcccccc}
\hline Model & df & R.d. & M.d. & F & P & AIC \\
\hline Null & 47 & 2.20 & & & & 2.25 \\
Body size (best model) & $\mathbf{1 , 4 6}$ & $\mathbf{0 . 8 9}$ & $\mathbf{1 . 3 1}$ & $\mathbf{6 7 . 2}$ & $<\mathbf{0 . 0 0 0 1}$ & $\mathbf{0 . 9 8}$ \\
Order & 2,45 & 1.47 & 0.74 & 11.3 & $<0.01$ & 1.76 \\
Body size + Order & 3,44 & 0.84 & 1.37 & 24.14 & $<0.001$ & 0.99 \\
Body size + Order + interaction & 5,42 & 0.81 & 1.40 & 14.5 & $<0.0001$ & 1.04 \\
\hline
\end{tabular}

R. d. - residual deviance, i. e. deviance not accounted for by model predictors. M. d.- model deviance, i. e. deviance accounted for by model predictors. AIC - Value of Akaike information criterion, which weights the amount of explained deviance by degrees of freedom, thus penalizing redundant predictors. The best model is in bold. 
TABLE 2. Regression of the preference for young leaves on body size in leaf-chewing insect communities and taxa feeding on Ficus wassa in Papua New Guinea. Significant regressions are in bold.

\begin{tabular}{lccccc}
\hline & $\mathrm{N}$ & $\mathrm{a}(\mathrm{SE})$ & $\mathrm{b}(\mathrm{SE})$ & $\mathrm{r}^{2}$ & $\mathrm{P}$ \\
\hline Entire community & $\mathbf{4 8}$ & $\mathbf{1 . 3 9}(\mathbf{0 . 0 7})$ & $-\mathbf{0 . 1 1}(\mathbf{0 . 0 1})$ & $\mathbf{0 . 5 9 4}$ & $<\mathbf{0 . 0 0 1}$ \\
Coleoptera & $\mathbf{2 3}$ & $\mathbf{1 . 3 7}(\mathbf{0 . 0 8})$ & $-\mathbf{0 . 1 0}(\mathbf{0 . 0 2})$ & $\mathbf{0 . 5 7 4}$ & $<\mathbf{0 . 0 0 1}$ \\
Chrysomelidae & 15 & $1.27(0.14)$ & $-0.07(0.04)$ & 0.197 & 0.097 (n.s.) \\
Rhyparida (Chrysomelidae) & $\mathbf{1 0}$ & $\mathbf{1 . 7 7}(\mathbf{0 . 1 7})$ & $\mathbf{- 0 . 2 0}(\mathbf{0 . 0 5})$ & $\mathbf{0 . 6 1 3}$ & $<\mathbf{0 . 0 1}$ \\
Curculionidae & $\mathbf{8}$ & $\mathbf{1 . 3 2}(\mathbf{0 . 0 9})$ & $\mathbf{- 0 . 1 0 ( 0 . 0 2 )}$ & $\mathbf{0 . 8 4 2}$ & $<\mathbf{0 . 0 0 5}$ \\
Lepidoptera & $\mathbf{1 1}$ & $\mathbf{1 . 5 2}(\mathbf{0 . 2 1})$ & $\mathbf{- 0 . 1 2 ( \mathbf { 0 . 0 4 } )}$ & $\mathbf{0 . 5 2 9}$ & $<\mathbf{0 . 0 5}$ \\
Orthopteroids & 14 & $0.99(0.39)$ & $-0.05(0.06)$ & 0.056 & 0.415 (n.s.) \\
Orthoptera & 10 & $0.98(0.48)$ & $-0.05(0.07)$ & 0.055 & $0.516($ n.s.) \\
Caelifera & 7 & $0.64(0.48)$ & $-0.00(0.08)$ & 0.000 & 0.968 (n.s.) \\
Ensifera & 3 & not tested & & &
\end{tabular}

Parameters of regressions between preference for young leaves $(Y)$ and body $\operatorname{size}(B): Y=\mathrm{a}+\mathrm{b} \ln B ; \mathrm{N}-$ number of species; $\mathrm{r}^{2}-$ variance explained, $\mathrm{P}$ - significance. All orders, families and genera with data for at least 5 species were analyzed separately.

\section{RESULTS}

In total, the data on feeding preferences were obtained for 6538 individuals of 183 species. More than 5 test results were available for 48 species (composition in Table 2), which were included in the analysis. These 48 species were represented by 6144 individuals $(93.97 \%$ of total data), which suggests that all locally common species of leaf-chewing herbivores from $F$. wassa were tested.

In single-term regressions of feeding preferences, both the insect order and the species body size were significant predictors of leaf preference (Table 1). Small insects preferred young leaves more then large insects. The model that included body size had the lowest AIC value of all possible models (i.e., models with body size, order, both terms and their interaction). In addition, comparison of higher-order models with the model containing body size

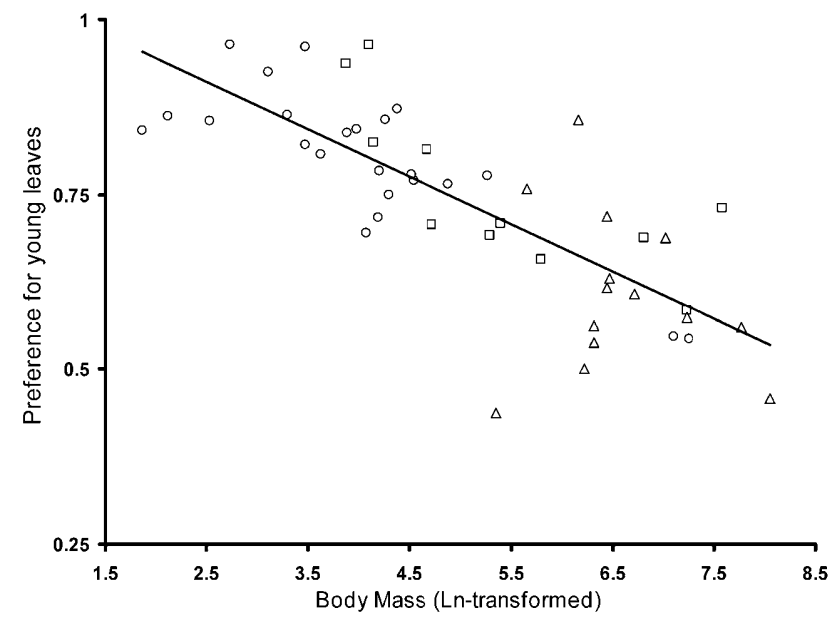

Fig. 1. The relationship between body size index $\left(B\right.$, in $\left.\mathrm{mm}^{3}\right)$ and preference for young leaves $(Y)$ in the leaf-chewing insect community feeding on Ficus wassa in Papua New Guinea. Coleoptera (circles), Lepidoptera (squares), Orthopteroids (triangles), a linear regression fitted for all insect species in the community showed that neither order, nor the interaction body size * order, improved model fit (body size vs. body size + order, $\mathrm{F}=1.6, \mathrm{P}=0.21$; body size vs. body size + order + interaction, $\mathrm{F}=0.6, \mathrm{P}=0.55$ ). The analyses thus show that body size alone is a good predictor of the patterns in preference for young leaves, whereas insect order is redundant in explaining feeding preferences.

This result was supported by regressions of feeding preferences against body size within individual orders, families and a genus (Fig. 2a, b, c; Table 2). Feeding preference for young leaves was negatively related to body size within the entire leaf-chewing community (Fig. 1), as well as within several taxa, from ordinal to generic levels (Table 2). In particular, the orders Lepidoptera (Fig. 2a) and Coleoptera (Fig. 2b) exhibited a significant negative relationship between body size and preference for young leaves, while considerably larger Orthopteroids did not (Fig. 2d). Curculionidae, one of the two families sufficiently speciose to permit a separate analysis, showed a significant negative relationship (Fig. 2c). Rhyparida (Chrysomelidae), the only genus permitting the analysis, also showed a significant negative relationship (Fig. 2c). Most of the non-significant associations were also negative (Table 2) and since the probability levels appear to be strongly dependent on sample size, some of them might become significant with larger samples.

\section{DISCUSSION}

\section{Body size and feeding preferences: empirical patterns}

It has been demonstrated here that small leaf-chewing herbivorous insects exhibited a strong preference for young leaves, while large species were less discriminating. This was the case for the entire leafchewing community and its constituent taxa. The GLM regression revealed that the differences in preference for young leaves were due to differences in body size within taxa. This pattern suggests that there are universal constraints on processing low-quality food, such as mature leaves, associated with small body size. 

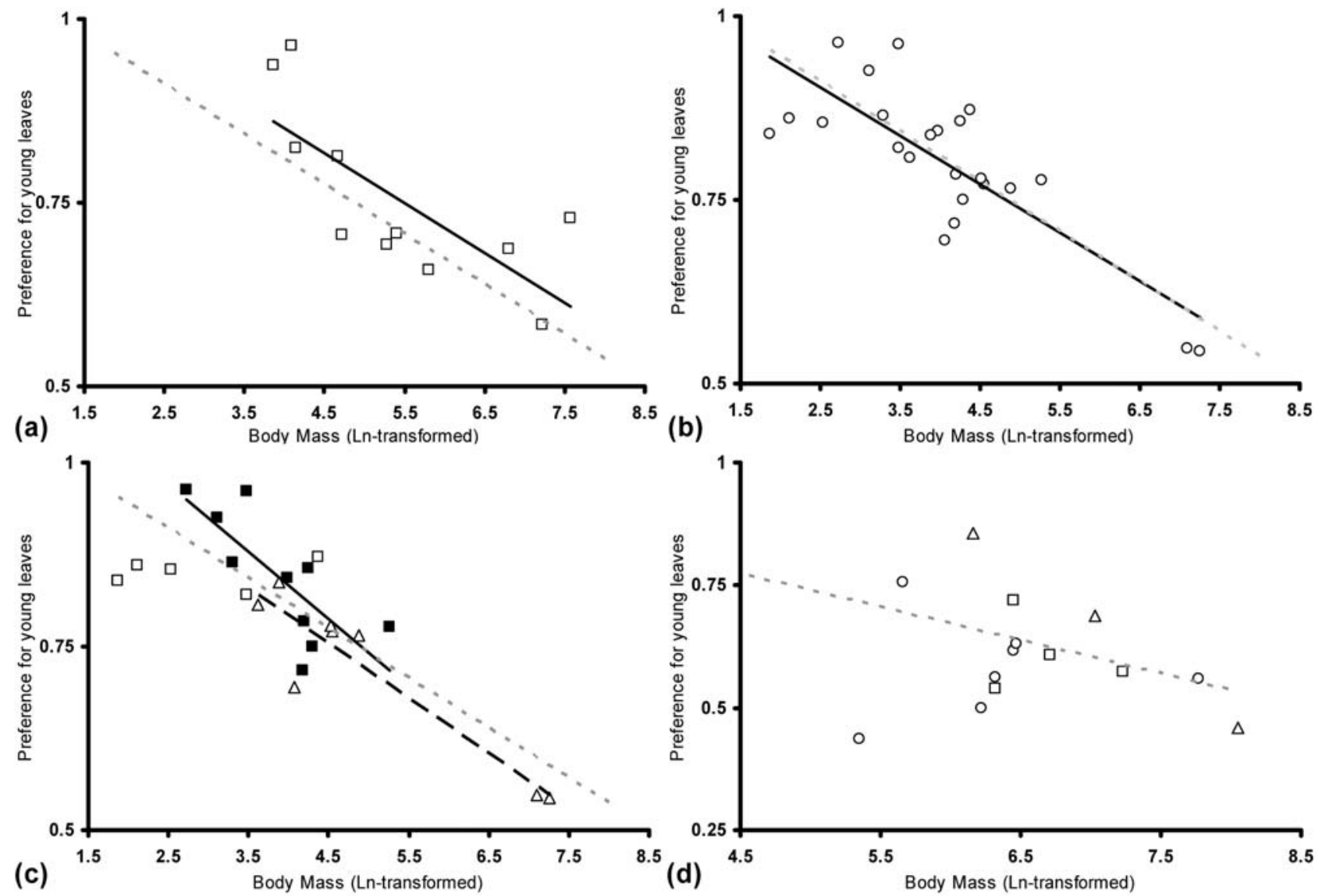

Fig. 2. The relationship between body size index $\left(B\right.$, in $\left.\mathrm{mm}^{3}\right)$ and preference for young leaves $(Y)$ in the leaf-chewing insect community feeding on Ficus wassa in Papua New Guinea. (a) - Lepidoptera; a linear regression fitted for Lepidoptera (solid line) and for all species in the community (grey broken line); (b) - Coleoptera: a linear regression fitted for Coleoptera (solid line) and for all species in the community (grey broken line); (c) - Coleoptera: Curculionidae (triangles), Chrysomelidae (squares), Rhyparida: Chrysomelidae (black squares); a linear regression fitted for Curculionidae (black broken line), Rhyparida (solid line) and for all species in the community (grey broken line); (d) - Orthopteroids: Caelifera (circles), Ensifera (triangles), Phasmatodea (squares); a linnear regression fitted for all species in the community (grey broken line). The index $Y$ ranges from 0 (mature leaf specialists) through 0.5 (indiscriminate feeding) to 1 (young leaf specialists). Regression equations are reported in Table 2.

Variety of observations suggests that small individuals and species have a more restricted diet than larger ones. Such observations are, however, limited to one or a few species of limited taxonomic range. Low food quality affects early instars, i.e. small insect larvae more than conspecific larvae from later instars (Reavey, 1993; Wheeler et al., 1998), and early larval instars often feed only on young leaves, while later instars can also utilize mature leaves (Feeny, 1970; Jones \& Ives, 1979; Larsson \& Ohmart, 1988; Floater, 1997).

Small species capable of feeding on mature leaves exist, but they often employ specialized feeding strategies, such as leaf mining, skeletonizing or leaf scraping, which allows them to select the highest-quality tissues of mature leaves (Feeny, 1970; Gaston et al., 1991; Choong, 1996; Powell et al., 1999; Shibata et al., 2001).

In comparison with mature leaves, young leaves are a higher quality resource, but also a resource that is spatially and temporally restricted. Herbivores have to expend more energy to locate them and run a higher risk of starvation when they fail to do so (Futuyma \& Moreno,
1988; Van Dongen et al., 1997; Jones, 2001). Below examine how the balance of costs and benefits associated with feeding on young foliage depends on body size.

\section{Why do small insects avoid mature leaves?}

Since toughness and nutritive value appear to be the only known factors which may affect body-size dependent preferences in respect to leaf age, the process of acquisition of nutrients from leaf tissue was examined in order to determine, which of these two traits may affect the preference.

The acquisition of nutrients from leaf tissue by insects can be described as a three-step process (see Woods \& Kingsolver, 1999), including (i) consumption - cutting and chewing the food; (ii) digestion - breakdown of ingested nutrients into fragments; and (iii) absorption across the gut epithelium.

(i) Consumption - The cutting and chewing of tough leaves is clearly more energetically demanding than the consumption of tender leaves. Hence, small herbivores may not be mechanically capable of feeding on mature leaves. There is a clear link between body size and 
feeding preferences, as the ability to cut through leaves depends on head capsule size, mass of chewing muscles and mandible morphology (Bernays, 1986; Bernays \& Janzen, 1988; Hochuli, 2001).

(ii) Digestion - Both toughness and low nutrient content can negatively affect breakdown of ingested nutrients (Reavey, 1993). Toughness may affect the size of ingested food particles, i.e. percentage of uncrushed vs. crushed cells. Though, Barbehenn (1992) has demonstrated the ability of insects to extract nutrients from uncrushed cells. Low nutrient content of food may result in lower secretion of digestive enzymes into the gut lumen (Ishaaya et al., 1971), but the importance of this mechanism for insect herbivores is unclear (Broadway \& Duffey, 1986). Further, the digestibility of food increases with food residence time in the gut, which is longer in larger species (Demment \& Van Soest, 1985; Yang \& Joern, 1994b).

(iii) Absorption - The absorption efficiency of digested nutrients is also positively correlated with gut size (i.e., body size). The efficiency of absorption in the gut may be a factor limiting nutrient intake in insect herbivores (Woods \& Kingsolver, 1999). Thus larger body size is probably associated with higher digestibility of food, as well as absorption efficiency. Larger body size may thus partly compensate for decreased diet quality. The expected isometric decrease in gut size with body size (Yang \& Joern, 1994b) would result in lower digestion and absorption efficiencies in small species. Small species and individuals, or individuals fed low nutrient food, have often relatively larger guts (Yang \& Joern, 1994a; Woods, 1999).

Insect herbivores use various strategies to cope with low dietary nutrient content. Compensatory feeding, i.e. consuming more food, is the most common (Yang \& Joern, 1994b; Woods, 1999). As the decreasing nutrient level is accompanied by increasing toughness in maturing leaves, the possibility to compensate for lower nutrient content by increased food consumption disappears. Thus leaf toughness and low nutrient content could be seen as complementary defense mechanisms affecting herbivores of small body size. This is the case particularly in plants that mainly use quantitative secondary compounds for defense (Feeny, 1976; Rhoades \& Cates, 1976).

\section{Conclusions}

In the whole community, body size explains most feeding preferences in respect to leaf age. The constraints imposed on diet selection by small leaf chewing insects, whether caused by toughness and/or low nutrient content, have important implications for insect seasonality and spatial distribution. Young leaves are scarce, there is therefore more food available for large than for small insect herbivores. In seasonal environments, the "phenological window of opportunity" (Hunter \& Lechowicz, 1992; Martel \& Kause, 2002), when young leaves are available, is short and determines the population dynamics of small insect herbivores, as well as early instars of larger species, as was demonstrated for European butterflies (Čížek et al., in prep.).
Other rapidly growing tissues, such as flowers, buds and developing fruits, also represent high-quality resources exploited by leaf-chewing insects, and are often preferred to mature foliage (Matter et al., 1999; Alonso \& Herrera, 2000; Ødegaard, 2000). These resources are likely to be exploited particularly by small species and early instars.

Host plant range is also affected by body size on intraand inter-specific levels, as demonstrated for grasshoppers (Sword \& Dopman, 1999), Lepidoptera (Wasserman \& Mitter, 1978) and Auchenorrhyncha (Novotný \& Basset, 1999). Small body size thus appears to be associated with restricted diets in terms of both, the leaf age and the number of host plants. Toughness and low nutrient content differ on both, intra-specific (leaf age) and inter-specific levels. As an insect grows, it becomes capable of feeding not only on tougher leaves of its original host plant, but also on leaves of other plants. Therefore, it is possible, that body-size related restriction of host plant range is caused by similar factors, as the diet restriction in terms of leaf age.

Ecologists often focus on the host specificity of herbivorous insects, especially in the tropics. Given the low host specificity of leaf chewing insects in the tropics (Novotný et al., 2002), results of this study suggest that phenological specialization also plays an important role, which, however, is poorly known and overlooked.

ACKNOWLEDGEMENTS. Parataxonomists J. Auga, W. Boen, C. Dal, S. Hiuk, B. Isua, M. Kasbal, R. Kutil, M. Manumbor and K. Molem assisted with technical aspects of the project. J. Ab, P. Damag, S. Kutil, T. Pius and A. Tombera collected insect specimens. This manuscript came into existence thanks to the support and supervision of V. Novotný and M. Konvička, and benefited from comments by Y. Basset, R.J. Morris and A. Woods. The project was funded by U.S. National Science Foundation (DEB-97-07928, DEB-02-11591), Czech Academy of Sciences (A6007106), Czech Ministry of Education (ES 041; FRVS 1263/2002), Czech Grant Agency (206/99/1115) and a Mattoni Fellowship.

\section{REFERENCES}

Agetsuma N. 2001: Relation between age-sex classes and dietary selection of wild Japanese monkeys. Ecol. Res. 16: 759-763.

Ahrens M.J., Hertz J., Lamoureux E.M., Lopez G.R., McElroy A.E. \& Brownawell B.J. 2001: The effect of body size on digestive chemistry and absorption efficiencies of food and sediment-bound organic contaminants in Nereis succinea (Polychaeta). J. Exp. Mar. Biol. Ecol. 263: 185-209.

AIDE T.M. 1988: Herbivory as a selective agent on the timing of leaf production in a tropical understorey community. Nature 336: $574-575$.

Alonso C. \& Herrera C.M. 2000: Seasonal variation in leaf characteristics and food selection by larval noctuids on an evergreen Mediterranean shrub. Acta Oecol. 21: 257-265.

BARBEHENN R.V. 1992: Digestion of uncrushed leaf tissues by leaf-snipping larval Lepidoptera. Oecologia 89: 229-235.

BARONE J.A. 2000: Comparison of herbivores and herbivory in the canopy and understory for two tropical tree species. Biotropica 32: 307-317. 
BASSET Y. 1991a: Influence of leaf traits on the spatial distribution of insect herbivores associated with an overstorey rainforest tree. Oecologia 87: 388-393.

BASSET Y. 1991b: Leaf production on an overstorey rainforest tree and its effect on the temporal distribution of associated insect herbivores. Oecologia 88: 211-219.

Basset Y. \& Novotný V. 1999: Species richness of insect herbivore communities on Ficus in Papua New Guinea. Biol. J. Linn. Soc. 67: 477-499.

Benavides A.G., Cancino J.M. \& OJeda F.P. 1994: Ontogenetic changes in gut dimensions and macroalgal digestibility in marine herbivorous fish, Aplodactylus punctatus. Funct. Ecol. 8: $46-51$.

Bernays E.A. 1986: Diet-induced head allometry among foliage-chewing insects and its importance for graminivores. Science 231: 495-497.

Bernays E.A. \& JANZEN D.H. 1988: Saturniid and Sphingid caterpillars - 2 ways to eat leaves. Ecology 69: 1153-1160.

Broadway R.M. \& Duffey S.S. 1986: The effect of dietary protein on the growth and digestive physiology of larval Heliothis zea and Spodoptera exigua. J. Insect Physiol. 32: 673-680.

Choong M.F. 1996: What makes a leaf tough and how this affects the pattern of Castanopsis fissa leaf consumption by caterpillars. Funct. Ecol. 10: 668-674.

Coley P.D. 1983: Herbivory and defensive characteristics of tree species in a lowland tropical forest. Ecol. Monogr. 53: 209-233.

Coley P.D. \& Barone J.A. 1996: Herbivory and plant defenses in tropical forests. Annu. Rev. Ecol. Syst. 27: 305-335.

Conradt L., Clutton-Brock T.H. \& Thomson D. 1999: Habitat segregation in ungulates: are males forced into sub-optimal foraging habitats through indirect competition by females? Oecologia 119: 367-377.

Demment M.W. \& Van Soest P.J. 1985: A nutritional explanation for body-size patterns of ruminant and nonruminant herbivores. Am. Nat. 125: 641-672.

Dussourd D.E. \& DenNo R.F. 1991: Deactivation of plant defense: correspondence between insect behaviour and secretory canal architecture. Ecology 72: 1383-1396.

Eggelton P., Davies R.G. \& Bignell D.E. 1998: Body size and energy use in termites: The responses of soil feeders and wood feeders differ in tropical forest assemblage. Oikos 81: $525-530$.

Farrell B.D., Dussourd D.E. \& Mitter C. 1991: Escalation of plant defense: Do latex and resin kanals spur plant diversification? Am. Nat. 138: 881-900.

FeENy P. 1970: Seasonal changes in oak leaf tannins and nutrients as a cause of spring feeding by winter moth caterpillars. Ecology 51: 565-581.

FEENY P. 1976: Plant apparency and chemical defense. Rec. $A d v$. Phytochem. 10: 1-40.

Fleming T.H. 1991: The relationship between body size, diet, and habitat use in frugivorous bats, genus Carollia (Phylostomatidae). J. Mammal. 72: 493-501.

FLOATER G.J. 1997: Rainfall, nitrogen and host plant condition: consequences for the processionary caterpillar, Orchogaster lunifer. Ecol. Entomol. 22: 247-255.

Futuyma D.J. \& Moreno G. 1988: The evolution of ecological specialization. Annu. Rev. Ecol. Syst. 19: 207-233.

Gaston K.J., Reavey D. \& Valladares G.R. 1991: Changes in feeding habit as caterpillars grow. Ecol. Entomol. 16: 339-344.

HiraKaWA H. 1997: Digestion-constrained optimal foraging in generalist mammalian herbivores. Oikos 78: 37-47.
Hochuli D.F. 2001: Insect herbivory and ontogeny: How do growth and development influence feeding behavior, morphology and host plant use? Austral Ecol. 26: 536-570.

Hume I.D., Jazwinski E. \& Flannery T.F. 1993: Morphology and function of the digestive-tract in New Guinean possums. Aust. J. Zool. 41: 85-100.

Hunter A.F. \& Lechowicz M.J. 1992: Foliage quality changes during canopy development of some northern hardwood trees. Oecologia 89: 316-323.

IshaAya I., Moore I. \& Joseph D. 1971: Protease and amylase activity in larvae of the Egyptian cotton worm, Spodoptera littoralis. J. Insect Physiol. 17: 945-953.

JONES R.E. 2001: Mechanisms for locating resources in space and time: Impact on the abundance of insect herbivores. Austral Ecol. 26: 518-524.

Jones R.E. \& Ives P.M. 1979: The adaptiveness of searching and host selection behaviour in Pieris rapae. Aust. J. Ecol. 4: 75-86.

Kleiber M. 1975: The Fire of Life: An Introduction to Animal Energetics. Krieger, Huntington, New York, 478 pp.

LARSSON S. \& OHMART P. 1988: Leaf age and larval performance of the leaf beetle Paropsis atomaria. Ecol. Entomol. 13: $19-24$.

LePš J., NovotnÝ V. \& BAsset Y. 2001: Habitat and successional status of plants in relation to the communities of their leaf-chewing herbivores in Papua New Guinea. J. Ecol. 89: 186-199.

Martel J. \& Kause A. 2002: The phenological window of opportunity for early-season birch sawflies. Ecol. Entomol. 27: 302-307.

Matter S.F., Landry J.B., Greco A.M. \& Lacourse C.D. 1999: Importance of floral phenology and florivory for Tetraopes tetraophtalmus (Coleoptera: Cerambycidae): Tests at the population and individual level. Environ. Entomol. 28: 1044-1051.

McAlpine J.R., Keig G. \& Falls R. 1983: Climate of Papua New Guinea. CSIRO and Australian National University Press, Canberra, 200 pp.

NovotnÝ V. \& BASSET Y. 1999: Body size and host plant specialization: a relationship from a community of herbivorous insects from New Guinea. J. Trop. Ecol. 15: 315-328.

NovotnÝ N. \& WiLson M.R. 1997: Why there are no small species among xylem-sucking insects? Evol. Ecol. 11: 419-437.

Novotný V., Basset Y., Miller S.E., Drozd P. \& Č́ížek L. 2002: Host specialization of leaf-chewing insects in a New Guinea rainforest. J. Anim. Ecol. 71: 400-412.

ØDEGAARD F. 2000: The relative importance of trees versus lianas as host for phytophagous beetles (Coleoptera) in tropical forests. J. Biogeogr. 27: 283-296.

Powell J.A., Mitter C. \& Farrell B. 1999: Evolution of larval food preferences in Lepidoptera. In Kristensen N.P. (ed.): Lepidoptera, Moth and Butterflies. Vol. 1: Evolution, Systematics, and Biogeography. Walter de Gruyter, Berlin, pp. 403-422.

ReAvey D. 1993: Why body size matters to caterpillars. In Stamp N.E. \& Casey T.M. (eds): Caterpillars - Ecological and Evolutionary Constraints on Foraging. Chapman \& Hall, New York, pp. 248-279.

RhoAdes D.F. \& CAtes R.G. 1976: Toward a general theory of plant anti-herbivore chemistry. Rec. Adv. Phytochem. 10: $168-213$.

S-Plus 2000 1999: Guide to Statistics. Vol. 1. MathSoft, Data Analysis Products Division, Seattle, Washington.

SCRIBER J.M. \& SlanSKY F. JR. 1981: The nutritional ecology if immature insects. Annu. Rev. Entomol. 26: 183-211. 
Shibata S., Ishida T.A., Soeya F., Morino M., Yoshida K., Sato H. \& Kimura M.T. 2001: Within-tree variation in density and survival of leafminers on oak Quercus dentata. Ecol. Res. 16: 135-143.

Sword G.A. \& Dopman E.B. 1999: Developmental specialization and geographic structure of host plant use in a polyphagous grasshopper, Schistocerca emarginata (= lineata) (Orthoptera: Acrididae). Oecologia 120: 437-445.

Usongo L.I. \& Amubode F.O. 2001: Nutritional ecology of Preuss's red colobus monkey (Colobus badius preussi Rahm 1970) in Korup National Park, Cameroon. Afr. J. Ecol. 39: $121-125$

Van Dongen S., Backeljau T., Matthysen E. \& Dhondt A.A. 1997: Synchronization of hatching date with budburst of individual host trees (Quercus robur) in the winter moth (Operophtera brumata) and its fitness consequences. J. Anim. Ecol. 66: 113-121.

WASSERMAN S.S. \& MitTeR C. 1978: The relationship of body size to breadth of diet in some Lepidoptera. Ecol. Entomol. 3: $155-160$.

Wheeler G.S., VAN T.K. \& CENTER T.D. 1998: Herbivore adaptations to low-nutrient food: Weed biological control spe- cialist Spodoptera pectinicornis (Lepidoptera: Noctuidae) fed the floating aquatic plant Pistia stratiotes. Environ. Entomol. 27: 993-1000.

Woods H.A. 1999: Patterns and mechanisms of growth of fifthinstar Manduca sexta caterpillars following exposure to lowor high-protein food during early instars. Physiol. Biochem. Zool. 72: 445-454.

Woods H.A. \& Kingsolver J.G. 1999: Feeding rate and the structure of protein digestion and absorption in Lepidopteran midguts. Arch. Insect Biochem. 42: 74-87.

Yela J.L. \& Herrera C.M. 1993: Seasonality and lifecycles of woody plant-feeding noctuid moths (Lepidoptera: Noctuidae) in Mediterranean habitats. Ecol. Entomol. 18: 256-269.

YANG Y. \& JOERN A. 1994a: Gut size in relation to variable food quality and body size in grasshoppers. Funct. Ecol. 8: 36-45.

YANG Y. \& JoERN A. 1994b: Influence of diet quality, developmental stage, and temperature on food residence time in the grasshopper Melanopus diferentialis. Physiol. Zool. 67: 598-616.

Received January 10, 2005; revised April 11, 2005; accepted April 21, 2005 